\title{
Treatment Results for Stage III Laryngeal Cancer: Analysis of a Populational Database Using Propensity Scores
}

\author{
Hugo Fontan Köhler ${ }^{10}$ Genival Barbosa de Carvalho ${ }^{10}$ Luiz Paulo Kowalski1,2® \\ ${ }^{1}$ Department of Head and Neck Surgery and Otolaryngology, A C \\ Camargo Cancer Center, São Paulo, SP, Brazil \\ 2 Department of Head and Neck Surgery, Universidade Estadual \\ Paulista, São Paulo, SP, Brazil \\ Address for correspondence Hugo Fontan Köhler, MD, Rua Professor \\ Antônio Prudente, 211, São Paulo, SP, 01509-010, Brazil \\ (e-mail: hkohler75@gmail.com).
}

Int Arch Otorhinolaryngol 2022;26(3):e370-e379.

\begin{abstract}
\section{Keywords}

- laryngeal neoplasms

- propensity score

- prognosis

- surgery

- radiotherapy

Introduction Treatment of stage III laryngeal cancer suffered a major paradigm change with surgery being substituted by radiation therapy with chemotherapy. Objective To evaluate the oncological outcome of different treatment modalities for stage III laryngeal cancer using a population database.

Methods A population database representing patients treated in the state of São Paulo, Brazil, was analyzed. Demographic, clinical and treatment variables were included, and the outcomes of interest were disease-specific and overall survival. Propensity score with nearest neighbor matching was used to compensate for imbalances in treatment groups.

Results We retrieved data from 1,804 patients. In multivariate analysis, age, female gender, payment source, clinical $\mathrm{N}$ stage ( $\mathrm{cN}$ ) stages, and treatment modality were significant for disease-specific and overall survival. Patients submitted to surgery treatment had a significantly better disease-specific $(p<0.001)$ and overall survival $(p<0.001)$ compared with chemoradiation. Propensity score matching was based on $\mathrm{cN}$ stage, gender, age, topography, and payment modality, and allowed the pairing of 685 patients from each treatment modality. There was a significant difference in disease-specific survival favoring surgery-based treatment $(p=0.017)$.

Conclusion The treatment choice has a significant impact on survival in patients with stage III laryngeal cancer with surgery-based treatment being superior to chemoradiotherapy (CRT).
\end{abstract}

\section{Introduction}

The aim of cancer staging is to group patients with similar prognoses and to create categories with maximum separation between them. Clinical stage III laryngeal cancer corresponds to a heterogeneous group of patients with $\mathrm{T} 1-\mathrm{T} 2$

received

June 2, 2020

accepted after revision

November 21, 2020

published online

November 3, 2021
DOI https://doi.org/ 10.1055/s-0041-1726042. ISSN 1809-9777. tumors and a single metastatic lymph node $<3 \mathrm{~cm}$ and without extracapsular spread (N1), or patients with cT3 primary tumor without lymph node metastases (NO) or staged as $\mathrm{N} 1{ }^{1}$. Treatment of these patients depends on tumor extent and location, patient characteristics, experience of the

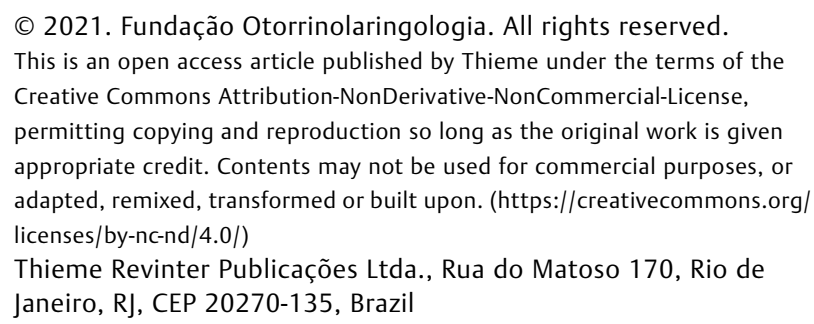


treating team with the options, and preferences and expectations of the patients. ${ }^{2}$

The usual treatment of laryngeal cancer was primarily surgical until the VA trial was published and caused a major shift in the approach of these patients, with the combination of radiotherapy (RT) and chemotherapy (CT) assuming a major role due to the high rates of larynx preservation reported. ${ }^{3}$ The following years made clear that larynx preservation per se was not an adequate endpoint due to the significant rates of laryngoesophageal dysfunction. The preservation of a dysfunctional larynx is not considered adequate. ${ }^{4,5}$ The concept of laryngeal function preservation using a nonsurgical treatment was further extended by the RTOG 91-11 trial, which compared sequential to simultaneous chemoradiation (CRT) with a significant advantage for the latter. ${ }^{6}$ The results of this trial were updated afterwards and showed a significant improvement in laryngeal preservation with simultaneous CRT, but overall survival was similar between the groups. Deaths not attributed to laryngeal cancer were higher in the simultaneous CRT group. ${ }^{7}$

These results were challenged by the analysis of retrospective and population-based databases. Chen et al. analyzed the National Cancer Database (NCDB) and found similar survival outcomes in stage III patients treated with surgery or CRT, but these were significantly better than exclusive RT. ${ }^{8}$ A further analysis of the same database disclosed a worsening survival for patients beginning in the mid-1990s, which was correlated with the shift from surgical to nonsurgical therapy. ${ }^{9}$ An analysis from the SEER database also confirmed that surgical treatment was associated with higher survival rates. ${ }^{10}$ But in a retrospective series from a single institution, this treatment shift was associated with worse survival in stage IV patients, but not in stage III patients. ${ }^{11}$ A meta-analysis of 15 studies showed a significant decrease in overall survival, disease-free survival, and locoregional control in T3 patients treated by laryngeal conservation protocol, but the number of patients enrolled in each study is small. ${ }^{12}$ For patients with CT3 laryngeal carcinoma, four options are equally listed in the National Comprehensive Cancer Network: concurrent systemic therapy/RT with isolated RT if the patient is not a good candidate for chemotherapy or surgery with or without adjuvant therapy, induction chemotherapy or participation in clinical trials. ${ }^{13}$

The main object of the present study is to analyze survival results of CT3 CNO-1 laryngeal cancer patients treated by surgery followed or not by adjuvant treatment or CRT in the state of São Paulo, Brazil, using a population-based database.

\section{Materials and Methods}

Data for the present report were obtained from the website of the Fundação Oncocentro (www.fosp.saude.sp.gov.br) and were downloaded on September $10^{\text {th }}, 2019$. These data are provided by several hospitals distributed across the entire state of São Paulo, both public and private, and contain standardized data collected from January 2000 to June 2019.
The inclusion criteria were topographical description code of C32 according to the International Disease Classification (IDC), morphological type of squamous cell carcinoma or its variants, lack of previous treatment, and clinical stage cT3 cN01-1 at diagnosis. Patients with in situ carcinoma or questionable stromal invasion at the morphological description were excluded from the present series. We also excluded patients treated by exclusive RT or other treatment combinations.

Statistical analysis was performed using the Stata 16 (Stata Corp., College Station, TX, USA) and R (R Foundation, Vienna, Austria) software. Categorical variables were described by their frequencies and continuous variables, by range, mean and standard deviation (SD). Proportion comparisons were performed by the chi-squared test, while two means were compared by the Student $t$-test. Multiple groups means were compared by analysis of variance (ANOVA). Survival analysis was performed by the KaplanMeier method followed by the log-rank test and Cox proportional hazard model. To compensate for the nonrandom allocation of patients among different treatments with variable distribution imbalance, a propensity score analysis was performed. Pairing was performed by the nearest neighbor method using a 0.02 calipers. All tests were considered bicaudal, and a p-value of 0.05 was considered statistically significant.

Since the data are anonymous and public, no consent from the Ethics Committee for Medical Research was sought.

\section{Results}

After application of the inclusion criteria, data from 1,804 patients were retrieved. The demographic, clinical, and treatment variables for the entire cohort are shown in - Table 1. There was a clear temporal trend of increase in nonsurgical treatment in the present series (-Fig. 1). The median time of follow-up was 33.5 months. At the last follow-up information, 156 patients $(8.7 \%)$ were alive with recurrent/persistent cancer, 670 patients were alive without evidence of disease (37.1\%), 649 patients (36.0\%) were dead from cancer, and 329 patients (18.2\%) were dead from other causes. The 5-year overall survival rate was of $45.34 \%$ (-Fig. 2), and the 5-year disease-specific survival was of $57.09 \%$ (-Fig. 3).

In the univariate disease specific survival analysis, there were significant differences according to age at diagnosis, gender, cT stage, cN stage, laryngeal topography and treatment modality (-Table 2 ). The same variables remained significant in the multivariate analysis, with laryngeal topography demonstrating a worse prognosis for supraglottic or other laryngeal locations (-Table $\mathbf{3}$ ). In a comparison of patients treated by surgery with or without adjuvant treatment versus CRT, a significant survival advantage was observed in the second group (hazard ratio [HR]: 1.325; 95\% confidence interval [CI]: 1.135-546; $p<0.001$, - Fig. 4). To evaluate the presence of immortal-time bias, we performed a landmark analysis at the time periods of 3 and 6 months focusing on treatment modalities (unimodal versus 
Table 1 Demographic, clinical, and treatment variables summary for the entire cohort

\begin{tabular}{|c|c|c|}
\hline Variable & Categories & $\begin{array}{l}\text { Number of patients } \\
\text { (frequency) }\end{array}$ \\
\hline \multirow[t]{2}{*}{ Gender } & Female & $237(13.1 \%)$ \\
\hline & Male & $1,567(86.9 \%)$ \\
\hline Age & Mean (SD) & $\begin{array}{l}60.5 \text { years old } \\
\text { ( } 9.9 \text { years old) }\end{array}$ \\
\hline \multirow[t]{4}{*}{ Insurance } & Private insurance & $57(3.2 \%)$ \\
\hline & Public health system & $722(40.0 \%)$ \\
\hline & Self-payment & $10(0.5 \%)$ \\
\hline & Undisclosed & $1,015(56.3 \%)$ \\
\hline \multirow[t]{5}{*}{ Topography } & Glottis & $540(29.9 \%)$ \\
\hline & Supraglottis & $394(21.8 \%)$ \\
\hline & Infraglottis & $16(0.9 \%)$ \\
\hline & Transglottic & $46(2.5 \%)$ \\
\hline & Unspecified & $808(44.8 \%)$ \\
\hline \multirow[t]{2}{*}{ cN stage } & cNO & $1,422(78.8 \%)$ \\
\hline & cN1 & $382(21.1 \%)$ \\
\hline \multirow{4}{*}{$\begin{array}{l}\text { Treatment } \\
\text { modality }\end{array}$} & Surgery & $370(20.5 \%)$ \\
\hline & Surgery + RT & 305 (16.9\%) \\
\hline & $\mathrm{RT}+\mathrm{CT}$ & 832 (46.1\%) \\
\hline & Surgery $+\mathrm{RT}+\mathrm{CT}$ & $298(16.5 \%)$ \\
\hline
\end{tabular}

Abbreviations: $\mathrm{CT}$, chemotherapy; RT, radiotherapy; SD, standard deviation.

multimodal). In the first landmark, 108 patients (5.98\%) were excluded from the analysis and, in the second landmark, 357 patients (9.25\%) were excluded. The unadjusted and adjusted HRs are shown in - Table 4.

We compared patients with glottic and supraglottic primary tumors. There are significant differences between the two populations regarding gender proportion, cN stage, age at diagnosis, and treatment modality employed ( $\mathbf{-}$ Table $\mathbf{5}$ ). After stratification for primary tumor site and using the landmark approach to reduce bias, we get two different survival models ( - Table 6). Treatment modality and cN stage were significant for both sites, while age was significant only for glottic primaries. Gender was not significant in any model.

To compensate for differences in patient allocation, propensity score matching was performed. Using $\mathrm{cN}$ stage, gender, age, topography, and payment modality, it was possible to match 685 patients from each group. The distribution of the propensity scores according to treatment is shown in - Fig. 5. The comparison of the survival curves by the log rank test showed a significant difference favoring the surgical group ( $p=0.017$, - Fig. 6).

With overall survival as the outcome of interest, a univariate analysis disclosed as significant the treatment modality, cN stage, primary tumor topography, payment modality, gender, and age ( - Table 7 ). Multivariate analysis showed the same variables as being significant ( - Table 8 ).

\section{Discussion}

We analyzed a public database containing information regarding stage III laryngeal cancer diagnosed in the state of São Paulo, Brazil. Since contribution to the database is voluntary, it does not represent the whole population, but a significant sample of it. Our major outcome of interest is survival, both disease-specific and overall. Since we have data focusing on a period of major transition from treatment modality, our major point of analysis is to compare surgery isolated or followed by adjuvant treatment versus chemoradiation.

In the present series, gender, age at diagnosis, tumor topography, cN stage, insurance status, and treatment modality were significantly associated with differences in survival rates. This finding correlates with a previous population-based series. ${ }^{8}$ Unfortunately, insurance status was missing from a significant number of patients, but its prognostic impact possibly relates to comorbidity and general health status, including differences in housing and nutrition, rather than quality of care or treatment facilities. In a series from the Ontario Cancer Registry, socioeconomic status was significant for survival in patients with glottic, but not with supraglottic laryngeal cancer with more advanced $\mathrm{T}$ stage, explaining 3 to $23 \%$ of this effect. ${ }^{14}$

Patients with cT3 cN0-1 stage III laryngeal cancer in this sample treated by primary surgery fared significantly better than those treated by CRT, and this difference remained after adjustment for nonrandom allocation by propensity score. This finding is unlike the VA trial ${ }^{3}$ but similar to those reported by Chen et al., whose patients treated by surgery followed or not by adjuvant treatment fared better than the CRT group. ${ }^{8}$ Another prospective randomized trial demonstrated similar disease-specific survival in patients treated by surgery and RT versus CRT with salvage surgery $(60 \%$ versus $50 \%$ ), and considers CRT a valid larynx preservation strategy. ${ }^{15}$ This finding demonstrates that our results are much closer to those reported by previous population-based analyses than those of prospective randomized trials conducted at tertiary centers. But a variable not recorded in the present series that significantly impacts survival is tumor volume. Patients with low volume (up to $3.5 \mathrm{~cm} 3$ ) cT3 tumors had higher survival rates when treated by exclusive RT. ${ }^{16}$ It calls attention that a careful patient selection using restrictive criteria may have a significant impact on the prognosis. In general, the overall survival for cT3 laryngeal cancers treated by exclusive RT ranges from $52^{17}$ to $83 \%{ }^{18} \mathrm{~A}$ significant limitation of these series are the not very clear inclusion criteria and the therapeutic selection bias. The nonrandom allocation of patients for different treatments was shown in a recent article using the NCDB. In patients with cT3/T4 laryngeal cancer, initial treatment with total laryngectomy or chemoradiation was more frequent in patients with low comorbidity index. Both modalities had comparable overall survival in patients with $\mathrm{cT} 3 \mathrm{cNx}$ primary 


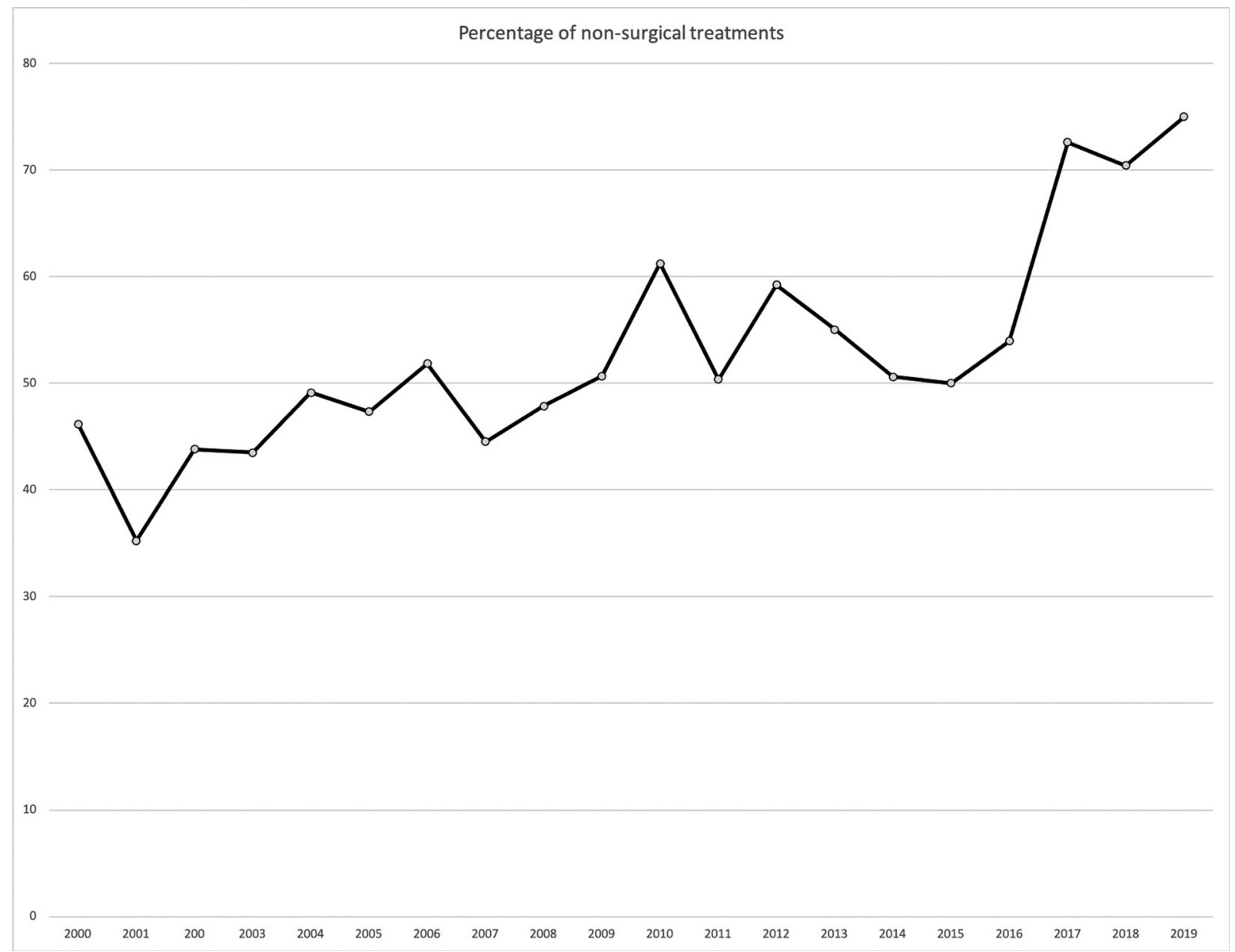

Fig. 1 Percentage of patients submitted to nonsurgical treatment according to year of treatment initiation.

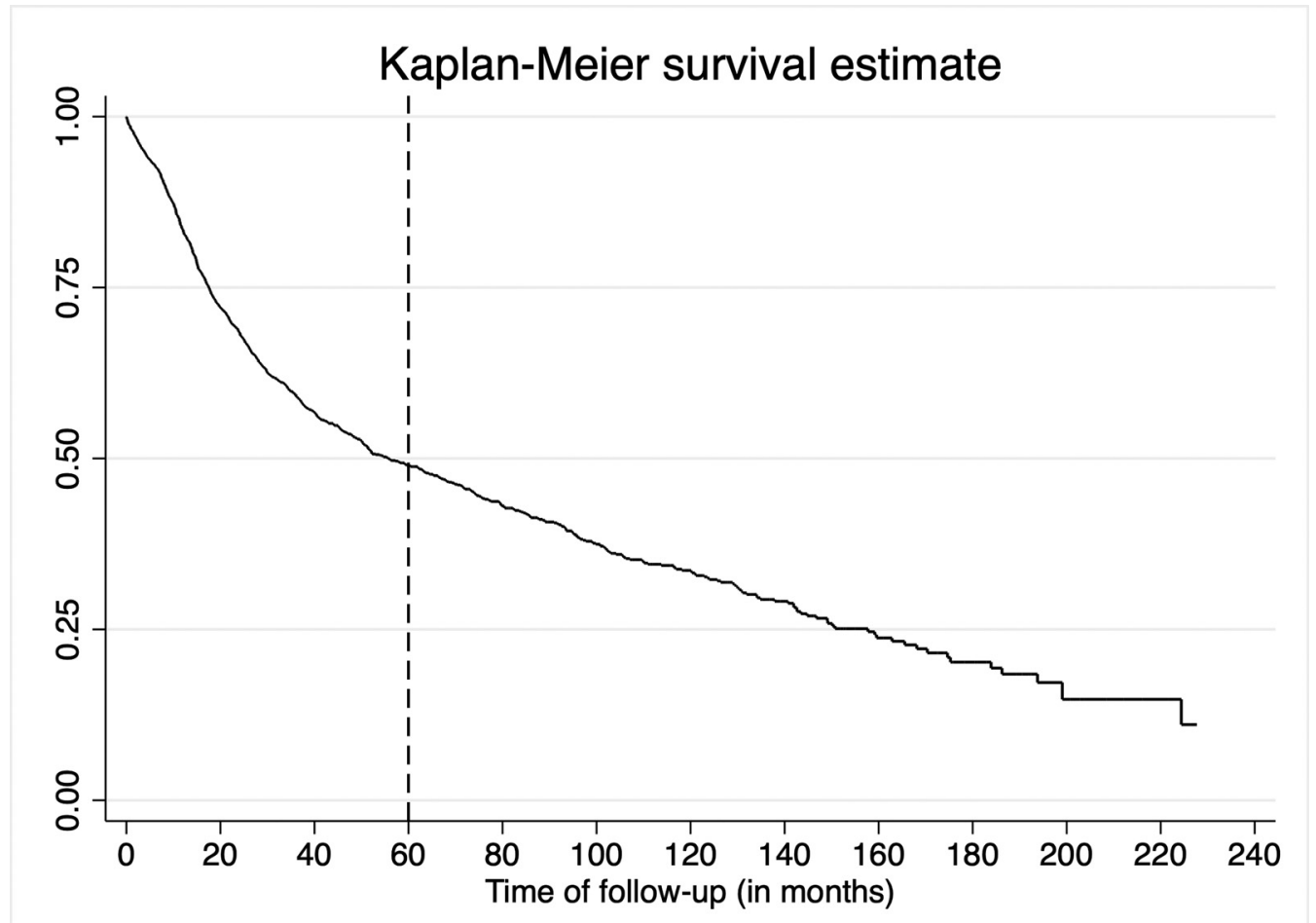

Fig. 2 Overall survival for patients included in the present series. The 5-year interval is indicated by the vertical dotted line. 


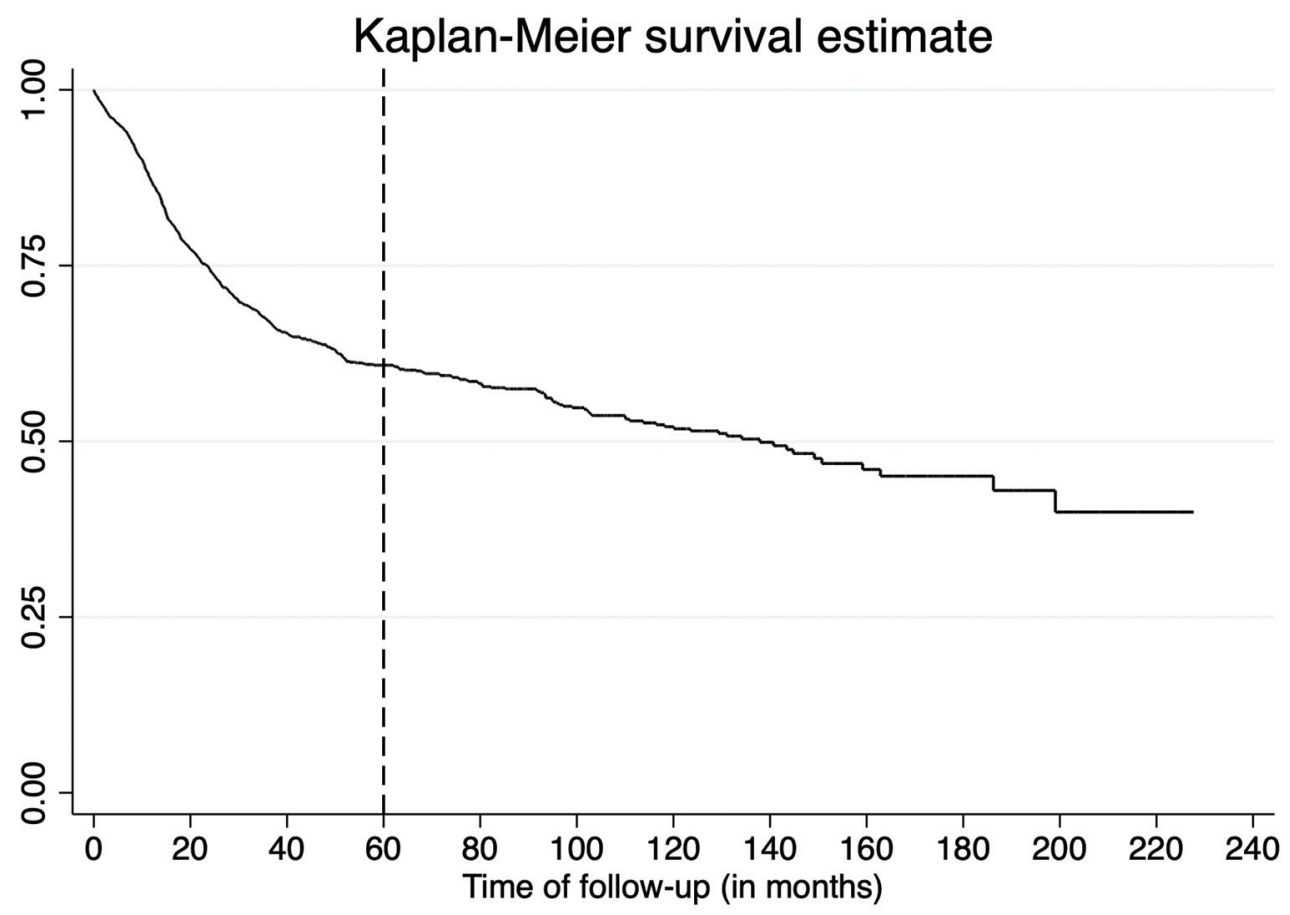

Fig. 3 Disease-specific survival for patients in the present series. The 5-year interval is indicated by the vertical dotted line.

Table 2 Univariate survival analysis with disease specific survival as the outcome of interest

\begin{tabular}{|l|l|l|l|l|}
\hline Variable & Values & Hazard ratio & $95 \% \mathrm{Cl}$ & $p$-value \\
\hline Gender & Male & 1 & & \\
\hline & Female & 0.7422 & $0.578-0.952$ & 0.019 \\
\hline Age & & 1.018 & $1.009-1.026$ & $<0.001$ \\
\hline Payer & Private Insurance & 1 & & \\
\hline & Public system & 1.959 & $1.039-3.695$ & 0.038 \\
\hline & Self-paid & 1.804 & $0.395-8.235$ & 0.446 \\
\hline & Not specified & 2.234 & $1.192-4.187$ & 0.012 \\
\hline Topography & Glottis & 1 & & $1.321-3.163$ \\
\hline & Supraglottis & 2.044 & $0.489-2.902$ & 0.001 \\
\hline & Subglottis & 1.191 & $1.033-1.617$ & 0.699 \\
\hline & Other locations & 1.293 & & 0.025 \\
\hline cN & cN0 & 1 & $1.321-1.874$ & \\
\hline & cN1 & 1.573 & & $<0.001$ \\
\hline Treatment & Surgery & 1 & $0.552-0.952$ & $1.001-1.517$ \\
\hline & Surgery+RT & 0.725 & $0.839-1.391$ & 0.021 \\
\hline & RT + CT & 1.232 & 0.547 \\
\hline & Surgery + RT + CT & 1.080 & \\
\hline
\end{tabular}

Abbreviations: $\mathrm{Cl}$, confidence interval; $\mathrm{CT}$, chemotherapy; RT, radiotherapy. 
Table 3 Multivariate survival analysis with disease specific survival as the outcome of interest

\begin{tabular}{|c|c|c|c|c|}
\hline Variable & Values & Hazard ratio & $95 \% \mathrm{Cl}$ & p-value \\
\hline \multirow[t]{2}{*}{ Gender } & Male & 1 & & \\
\hline & Female & 0.742 & $0.576-0.956$ & 0.021 \\
\hline Age & & 1.019 & $1.011-1.028$ & $<0.001$ \\
\hline \multirow[t]{4}{*}{ Payer } & Private Insurance & 1 & & \\
\hline & Public system & 2.116 & $1.187-3.770$ & 0.011 \\
\hline & Self-paid & 2.813 & $0.903-8.765$ & 0.074 \\
\hline & Not specified & 2.701 & $1.521-4.798$ & 0.001 \\
\hline \multirow[t]{2}{*}{$\mathrm{cN}$} & cNO & 1 & & \\
\hline & $\mathrm{cN} 1$ & 1.551 & $1.294-1.861$ & $<0.001$ \\
\hline \multirow[t]{4}{*}{ Treatment } & Surgery & 1 & & \\
\hline & Surgery + RT & 0.739 & $0.577-0.946$ & 0.016 \\
\hline & $\mathrm{RT}+\mathrm{CT}$ & 1.163 & $0.953-1.418$ & 0.137 \\
\hline & Surgery $+\mathrm{RT}+\mathrm{CT}$ & 1.052 & $0.831-1.332$ & 0.671 \\
\hline \multirow[t]{4}{*}{ Topography } & Glottis & 1 & & \\
\hline & Supraglottis & 1.284 & $1.057-1.559$ & 0.012 \\
\hline & Subglottis & 0.633 & $0.571-3.397$ & 0.467 \\
\hline & Other locations & 2.072 & $1.333-3.220$ & 0.001 \\
\hline
\end{tabular}

Abbreviations: $\mathrm{Cl}$, confidence interval; $\mathrm{CT}$, chemotherapy; $\mathrm{RT}$, radiotherapy.

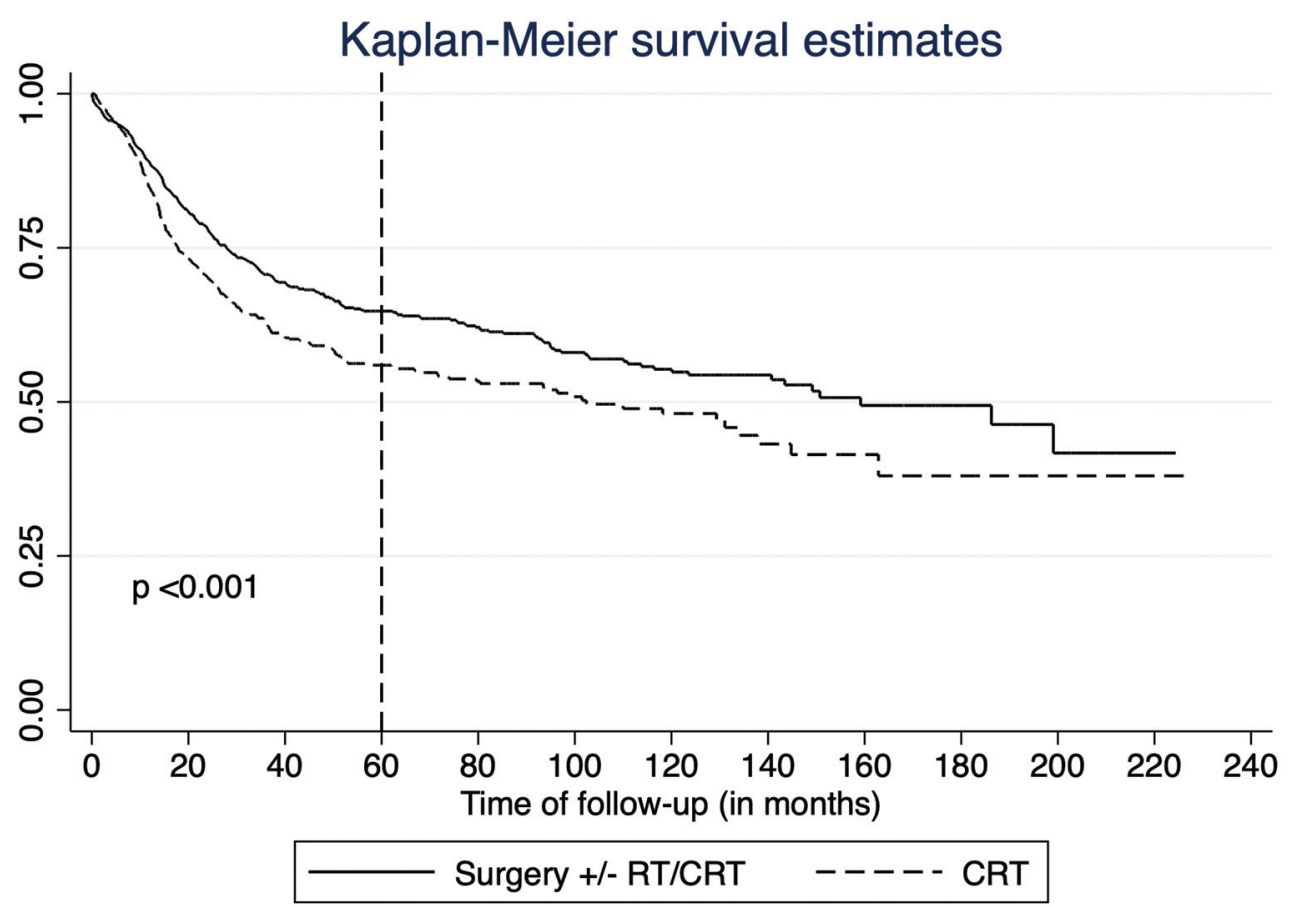

Fig. 4 Kaplan-Meier curves comparing single versus multimodal treatment. A significant survival advantage for patients submitted to surgery $+/$ - adjuvant treatment is visible.

tumors. ${ }^{19}$ In a single institution series, the authors demonstrate equivalent survivals for $\mathrm{CT} 3$ patients treated by primary surgery or CRT, but emphasize the role of strict selection criteria to achieve these results. ${ }^{20}$
The tumor primary site was significant for overall survival when comparing glottis with supraglottis and other locations in our series. This finding contrast with the analysis of a Norwegian series that demonstrated similar prognosis for 
Table 4 Landmark analysis of patients at the 3-and 6-month time points

\begin{tabular}{|c|c|c|c|c|c|}
\hline & & Unadjusted models & & Adjusted models & \\
\hline Survival model & Patients analyzed & $\mathrm{HR}(\mathrm{Cl})$ & p-value & $\mathrm{HR}(\mathrm{Cl})$ & p-value \\
\hline Base model & 1,804 & $0.804(0.696-0.928)$ & 0.003 & $1.297(1.111-1.514)$ & 0.001 \\
\hline Landmark at 3 months & 1,696 & $1.426(1.213-1.678)$ & $<0.001$ & 1.401 (1.191-1.649) & $<0.001$ \\
\hline Landmark at 6 months & 1,637 & $1.377(1.166-1.628)$ & $<0.001$ & $1.354(1.145-1.601)$ & $<0.001$ \\
\hline
\end{tabular}

Abbreviations: $\mathrm{Cl}$, confidence interval; $\mathrm{HR}$, hazard ratio.

The covariates were fixed at the lowest level, if categorical, or at the mean, if continuous. Surgery with or without adjuvant treatment was considered as reference.

Table 5 Comparison between the patients with glottic and supraglottic primary tumors

\begin{tabular}{|l|l|l|l|l|}
\hline Variable & Values & Glottic primary & Supraglottic primary & $p$-value \\
\hline Gender & Female & $49(9.1 \%)$ & $82(20.8 \%)$ & $<0.001$ \\
\hline & Male & $491(90.9 \%)$ & $312(79.2 \%)$ & \\
\hline Age & Mean (SD) & $61.35(9.89)$ & $59.94(9.03)$ & 0.025 \\
\hline cN & 0 & $487(90.2 \%)$ & $276(70.1 \%)$ & $<0.001$ \\
\hline & 1 & $53(9.8 \%)$ & $118(29.9 \%)$ & \\
\hline Treatment & Surgery + I- RT/CRT & $244(45.2 \%)$ & $253(64.2 \%)$ & $<0.001$ \\
\hline & CRT & $296(54.8 \%)$ & $141(35.8 \%)$ & \\
\hline
\end{tabular}

Abbreviations: $\mathrm{Cl}$, confidence interval; CRT, chemoradiotherapy; RT, radiotherapy; SD, standard deviation.

Table 6 Survival models according to primary tumor site (glottis versus supraglottis) with disease-specific survival as the outcome of interest

\begin{tabular}{|c|c|c|c|c|}
\hline Variables & Values & HR & $95 \% \mathrm{Cl}$ & $p$-value \\
\hline \multicolumn{5}{|l|}{ Glottic primary tumor } \\
\hline Age & & 1.034 & $1.018-1.051$ & $<0.001$ \\
\hline \multirow[t]{2}{*}{ Gender } & Male & 1 & & \\
\hline & Female & 1.061 & $0.613-1.838$ & 0.832 \\
\hline \multirow[t]{2}{*}{$\mathrm{cN}$} & 0 & 1 & & \\
\hline & 1 & 1.541 & $0.940-2.527$ & 0.086 \\
\hline \multirow[t]{2}{*}{ Treatment modality } & Surgery $+I-\mathrm{RT} / \mathrm{CRT}$ & 1 & & \\
\hline & CRT & 1.249 & $1.027-1.701$ & 0.015 \\
\hline \multicolumn{5}{|c|}{ Supraglottic primary tumor } \\
\hline Age & & 1.001 & $0.983-1.1019$ & 0.892 \\
\hline \multirow[t]{2}{*}{ Gender } & Male & 1 & & \\
\hline & Female & 0.761 & $0.492-1.175$ & 0.218 \\
\hline \multirow[t]{2}{*}{$\mathrm{cN}$} & 0 & 1 & & \\
\hline & 1 & 1.448 & $1.029-2.038$ & 0.034 \\
\hline \multirow[t]{2}{*}{ Treatment modality } & Surgery $+I-\mathrm{RT} / \mathrm{CRT}$ & 1 & & \\
\hline & CRT & 1.125 & $1.012-1.589$ & 0.041 \\
\hline
\end{tabular}

Abbreviations: $\mathrm{Cl}$, confidence interval; CRT, chemoradiotherapy; HR, hazard ratio; RT, radiotherapy.

both glottic and supraglottic cancers only in cT3 patients. ${ }^{21}$ In our series, CRT decreased disease-specific survival in glottic and supraglottic tumors.

A meta-analysis of 25 studies on treatment outcomes for T3 glottic carcinomas demonstrated that disease-specific and overall survival were comparable in the surgery, RT and CRT arms, but with an improved local control in the surgery and CRT arms. ${ }^{22}$ The data from the NCDB support the use of RT-based larynx preservation strategy. In a series of 2,622 patients, overall and disease-specific survival were 


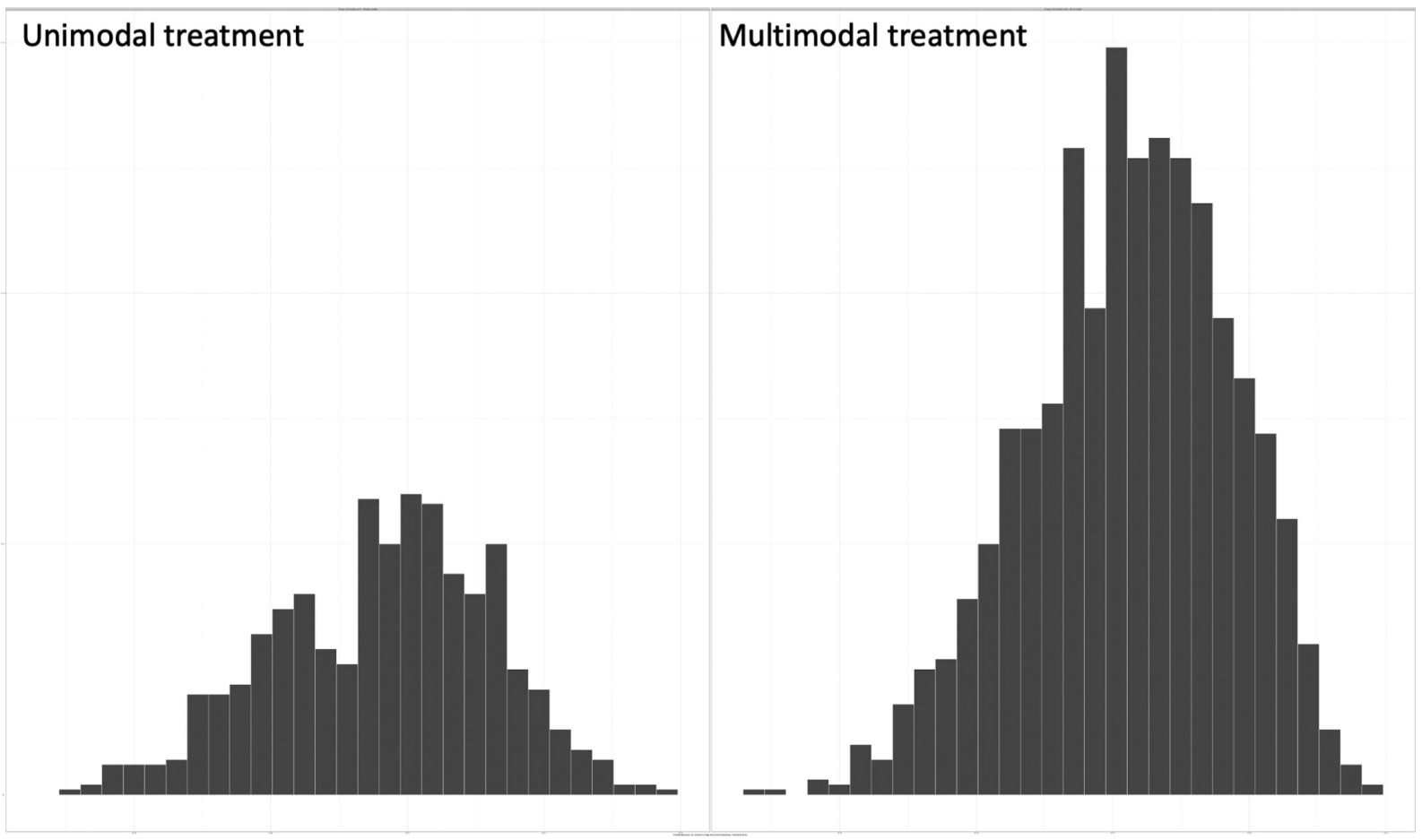

Fig. 5 Distribution of propensity score estimates according to treatment status.

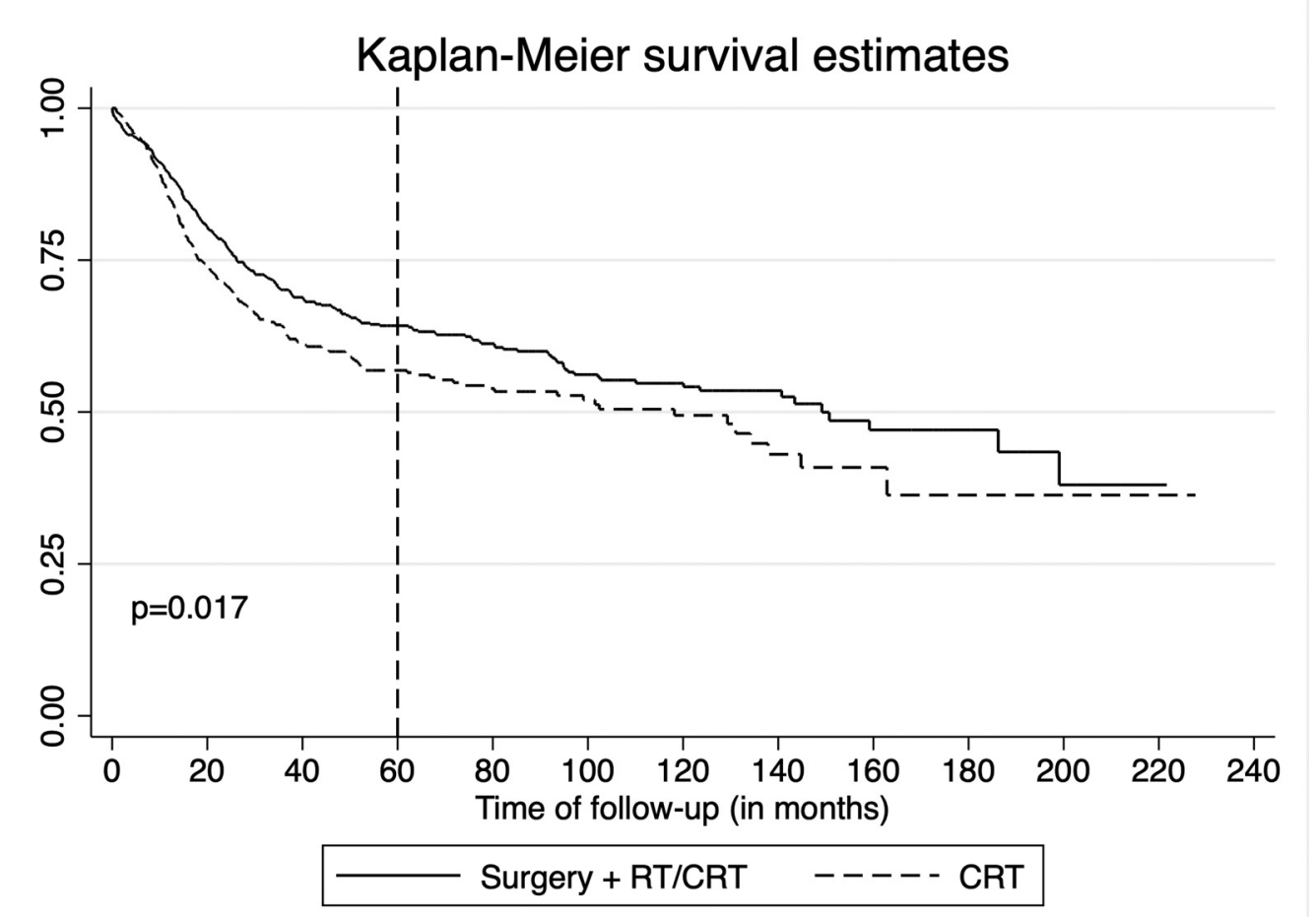

Fig. 6 Comparison of survival curves according to treatment modality after pairing by propensity score. In this cohort, a significant advantage for surgery-based treatments remains.

comparable between surgical and nonsurgical approaches. ${ }^{23}$ A more recent analysis of the same database reported that patients treated by CRT had a significant better survival than those submitted to primary surgery in univariate analysis, but this advantage was not retained in multivariate analy- sis. ${ }^{24}$ This may be related to nonrandom patient selection. But a retrospective series analyzing RT or CRT for cT3 $\mathrm{cNx}$ laryngeal carcinoma showed improved local control and laryngectomy-free survival with minimal increase in toxicity for patients submitted to CRT. ${ }^{25}$ Interestingly, Timmermans 
Table 7 Univariate survival analysis using overall survival as the outcome of interest

\begin{tabular}{|l|l|l|l|l|}
\hline Variable & Values & Hazard ratio & $95 \% \mathrm{Cl}$ & $p$-value \\
\hline Gender & Male & 1 & & \\
\hline & Female & 0.699 & $0.552-0.886$ & 0.003 \\
\hline Age & & 1.025 & $1.018-1.033$ & $<0.001$ \\
\hline Payer & Private Insurance & 1 & & \\
\hline & Public system & 2.387 & $1.227-4.641$ & 0.010 \\
\hline & Self-paid & 2.230 & $0.497-10.648$ & 0.287 \\
\hline & Not specified & 2.716 & $1.403-5.255$ & 0.003 \\
\hline Topography & Glottis & 1 & & \\
\hline & Supraglottis & 1.808 & $1.218-2.685$ & 0.003 \\
\hline & Subglottis & 1.123 & $0.529-2.388$ & 0.762 \\
\hline & Other locations & 1.292 & $1.056-1.582$ & 0.013 \\
\hline cN & cN0 & 1 & & \\
\hline & cN1 & 1.394 & $1.182-1.644$ & $<0.001$ \\
\hline Treatment & Surgery & 1 & & \\
\hline & Surgery + RT & 0.725 & $0.552-0.953$ & 0.021 \\
\hline & RT + CT & 1.232 & $1.000-1.517$ & 0.050 \\
\hline & Surgery+RT + CT & 0.979 & $0.839-1.391$ & 0.547 \\
\hline
\end{tabular}

Abbreviations: $\mathrm{Cl}$, confidence interval; CRT, chemoradiotherapy; RT, radiotherapy.

Table 8 Multivariate survival analysis using overall survival as the outcome of interest

\begin{tabular}{|l|l|l|l|l|}
\hline Variable & Values & Hazard ratio & $95 \% \mathrm{Cl}$ & $p$-value \\
\hline Gender & Male & 1 & & \\
\hline & Female & 0.742 & $0.576-0.956$ & 0.021 \\
\hline Age & & 1.019 & $1.011-1.028$ & $<0.001$ \\
\hline Payer & Private Insurance & 1 & & \\
\hline & Public system & 2.030 & $1.074-3.837$ & 0.029 \\
\hline & Self-paid & 2.044 & $0.446-9.360$ & 0.357 \\
\hline & Not specified & 2.371 & $1.261-4.461$ & 0.007 \\
\hline CN & CN0 & 1 & & \\
\hline & CN1 & 1.552 & $1.294-1.861$ & $<0.001$ \\
\hline Treatment & Surgery & 1 & & \\
\hline & Surgery+RT & 0.702 & $0.534-0.925$ & 0.012 \\
\hline & RT + CT & 1.212 & $0.977-1.504$ & 0.081 \\
\hline & Surgery + RT + CT & 1.111 & $0.860-1.434$ & 0.420 \\
\hline Topography & Glottis & 1 & & \\
\hline & Supraglottis & 2.072 & $1.333-3.220$ & 0.001 \\
\hline & Subglottis & 1.393 & $0.571-3.397$ & 0.467 \\
\hline & Other locations & 1.152 & $0.912-1.456$ & 0.235 \\
\hline
\end{tabular}

Abbreviations: $\mathrm{Cl}$, confidence interval; $\mathrm{CT}$, chemotherapy; $\mathrm{RT}$, radiotherapy.

et al. reported on the results from the Netherlands Cancer Institute showing no survival difference between $\mathrm{T} 3$ and $\mathrm{T} 4$ tumors. The treatment option, as dictated by institutional protocols, was nonsurgical for T3 patients and surgical for T4 patients. The authors suggest that the lack of a survival difference may be related to the treatment option. ${ }^{26}$ Our results show that surgery alone or associated with adjuvant treatment is superior to CRT. This result is in line with that reported by Chen et al., who favor surgery over nonsurgical approaches. $^{8}$ 


\section{Conclusion}

The treatment choice has a significant impact on survival in patients with stage III laryngeal cancer, with surgery-based treatments having improved outcome when compared with CRT. In this population, the results of the previously reported prospective randomized trials are not reproduced.

\section{Conflict of Interests}

The authors have no conflict of interests to declare.

\section{References}

1 Amin MB, Edge S, Greene F, Byrd DR, Brookland RK, Washington MK, Gershenwald JE, Compton CC, Hess KR, et al. (Eds.) AJCC Cancer Staging Manual (8th edition). Springer International Publishing: American Joint Commission on Cancer; 2017

2 Wheless SA, McKinney KA, Zanation AM. A prospective study of the clinical impact of a multidisciplinary head and neck tumor board. Otolaryngol Head Neck Surg 2010;143(05):650-654

3 Wolf GT, Fisher SG, Hong WK, et al; Department of Veterans Affairs Laryngeal Cancer Study Group. Induction chemotherapy plus radiation compared with surgery plus radiation in patients with advanced laryngeal cancer. N Engl J Med 1991;324(24): 1685-1690

4 Lefebvre JL, Ang KKLarynx Preservation Consensus Panel. Larynx preservation clinical trial design: key issues and recommendations-a consensus panel summary. Head Neck 2009;31(04): 429-441

5 Hutcheson KA, Lewin JS. Functional outcomes after chemoradiotherapy of laryngeal and pharyngeal cancers. Curr Oncol Rep 2012;14(02):158-165

6 Forastiere AA, Goepfert H, Maor M, et al. Concurrent chemotherapy and radiotherapy for organ preservation in advanced laryngeal cancer. N Engl J Med 2003;349(22):2091-2098

7 Forastiere AA, Zhang Q, Weber RS, et al. Long-term results of RTOG 91-11: a comparison of three nonsurgical treatment strategies to preserve the larynx in patients with locally advanced larynx cancer. J Clin Oncol 2013;31(07):845-852

8 Chen AY, Halpern M. Factors predictive of survival in advanced laryngeal cancer. Arch Otolaryngol Head Neck Surg 2007;133 (12):1270-1276

9 Hoffman HT, Porter K, Karnell LH, et al. Laryngeal cancer in the United States: changes in demographics, patterns of care, and survival. Laryngoscope 2006;116(9 Pt 2):(Suppl 111):1-13

10 Carvalho AL, Nishimoto IN, Califano JA, Kowalski LP. Trends in incidence and prognosis for head and neck cancer in the United States: a site-specific analysis of the SEER database. Int J Cancer 2005;114(05):806-816

11 Gourin CG, Conger BT, Sheils WC, Bilodeau PA, Coleman TA, Porubsky ES. The effect of treatment on survival in patients with advanced laryngeal carcinoma. Laryngoscope 2009;119 (07):1312-1317
12 Tang ZX, Gong JL, Wang YH, et al. Efficacy comparison between primary total laryngectomy and nonsurgical organ-preservation strategies in treatment of advanced stage laryngeal cancer: A meta-analysis. Medicine (Baltimore) 2018;97(21):e10625

13 NCCN Clinical Practice Guidelines in Oncology [Internet]. Plymouth Meeting: National Comprehensive Cancer Network; c. 2020 Accessed Aug 11, 2020 at: https://www.nccn.org/professionals/physician_gls/pdf/head-and-neck.pdf

14 Groome PA, Schulze KM, Keller S, et al. Explaining socioeconomic status effects in laryngeal cancer. Clin Oncol (R Coll Radiol) 2006; 18(04):283-292

15 Soo KC, Tan EH, Wee J, et al. Surgery and adjuvant radiotherapy vs concurrent chemoradiotherapy in stage III/IV nonmetastatic squamous cell head and neck cancer: a randomised comparison. Br J Cancer 2005;93(03):279-286

16 Mendenhall WM, Dagan R, Bryant CM, Amdur RJ, Mancuso AA. Definitive radio- therapy for squamous cell carcinoma of the glottic larynx. Cancer Contr 2016;23(03):208-212

17 Hinerman RW, Mendenhall WM, Morris CG, Amdur RJ, Werning JW, Villaret DB. T3 and T4 true vocal cord squamous carcinomas treated with external beam irradiation: a single institution's 35year experience. Am J Clin Oncol 2007;30(02):181-185

18 Issa MR, Samuels SE, Bellile E, Shalabi FL, Eisbruch A, Wolf G. Tumor Volumes and Prognosis in Laryngeal Cancer. Cancers (Basel) 2015;7(04):2236-2261

19 Bollig C, Ahmad J, Dooley L. Effect of medical comorbidities on treatment regimen and survival in T3/T4 laryngeal cancer. Laryngoscope 2020;130(06):1459-1464

20 Timme DW, Jonnalagadda S, Patel R, Rao K, Robbins KT. Treatment Selection for T3/T4a Laryngeal Cancer: Chemoradiation Versus Primary Surgery. Ann Otol Rhinol Laryngol 2015;124(11): 845-851

21 Brandstorp-Boesen J, Sørum Falk R, Boysen M, Brøndbo K. Impact of stage, management and recurrence on survival rates in laryngeal cancer. PLoS One 2017;12(07):e0179371

22 Kim BH, Park SJ, Jeong WJ, Ahn SH. Comparison of treatment outcomes for T3 glottic squamous cell carcinoma: a meta-analysis. Clin Exp Otorhinolaryngol 2018;11(01):1-8

23 Ko HC, Harari PM, Chen S, et al. Survival outcomes for patients with T3NOM0 squamous cell carcinomof the glottic larynx. JAMA Otolaryngol Head Neck Surg 2017;143(11):1126-1133

24 Bates JE, Amdur RJ, Morris CM, et al. Curative-dose chemoradiotherapy versus total laryngectomy for stage T3-T4 squamous cell carcinoma of the larynx. Am J Clin Oncol 2019;42(06): 527-533

25 Al-Mamgani A, Tans L, van Rooij P, Levendag PC. A single-institutional experience of 15 years of treating T3 laryngeal cancer with primary radiotherapy, with or without chemotherapy. Int J Radiat Oncol Biol Phys 2012;83(03):1000-1006

26 Timmermans AJ, de Gooijer CJ, Hamming-Vrieze O, Hilgers FJM, van den Brekel MW. T3-T4 laryngeal cancer in The Netherlands Cancer Institute; 10-year results of the consistent application of an organ-preserving/-sacrificing protocol. Head Neck 2015;37 (10):1495-1503 